\title{
Oblique Retro-Aortic Left Renal Vein and its Clinical Importance Bhagavath $P,{ }^{1}$ Nayak BS, ${ }^{2}$ Monteiro NPF, ${ }^{3}$ Kumar GP ${ }^{1}$
}

${ }^{1}$ Department of Forensic Medicine and Toxicology, Kasturba Medical College Manipal, Manipal University.

${ }^{2}$ Department of Anatomy,

Melaka Manipal Medical College (Manipal Campus), Manipal University, Manipal

${ }^{3}$ Department of Forensic Medicine and Toxicology, AJ Institute of Medical Sciences, Mangalore, India.

\section{Corresponding Author}

Satheesha Nayak B

Department of Anatomy,

Melaka Manipal Medical College (Manipal Campus), Manipal University, Manipal, India.

E-mail: nayaksathish@gmail.com

\section{Citation}

Bhagavath P, Nayak BS, Monteiro NPF, Kumar GP. Oblique Retro-Aortic Left Renal Vein and its Clinical Importance. Kathmandu Univ Med J 2015;52(4):369-71.

\begin{abstract}
Kidneys are the organs that remove the waste products of the metabolic activities. A smooth blood flow to the kidneys is essential to maintain their function. Abnormalities of the renal vasculature may result not only in impairing the renal function but can lead to conditions like varicocele. During an autopsy of an adult male, we observed renal vascular variations. The left renal vein had a retro-aortic course before its termination into the inferior vena cava. It was joined with the inferior vena cava at the level of inferior mesenteric artery with an acute angle. The left testicular vein joined the left renal vein with an acute angle. The right kidney was supplied by two renal arteries. The knowledge about retro-aortic course of the left renal vein may be important during renal transplantation. The oblique course of left renal vein and the termination of left testicular vein into it with an acute angle may increase the chances of left sided varicocele.
\end{abstract}

\section{KEY WORDS}

Inferior vena cava, kidney, renal vein, retro-aortic, variation

\section{INTRODUCTION}

The kidneys are situated close to the posterior abdominal wall retroperitoneally. Each kidney is supplied by a renal artery arising from the abdominal aorta and drained by a renal vein that terminates into the inferior vena cava. ${ }^{1}$ Several variations in the vascular pattern of the kidney have been reported. The kidney may be supplied by more than one renal artery and may be drained by more than one renal vein. ${ }^{1}$ The location and anatomy of the renovascular pedicle is of great value during surgical procedures on the abdominal aorta, superior mesenteric and renal arteries, splenorenal and mesorenal shunts, inferior vena caval interruption, sympathectomy, nephrectomy, and during operations on the renal pelvis. ${ }^{2}$ Atypical levels of drainage and anatomical variations of the renal veins are also vital in the selection of donors for renal transplantation and venin assays by inferior vena caval catheterization in diagnosis of patients with renovascular hypertension. ${ }^{2}$ We present the retro-aortic oblique course of the left renal vein and discuss its clinical importance in this report.

\section{CASE REPORT}

During the autopsy of an adult male aged 50 years, we found variations of the renal vessels. The left renal artery gave an extra-hilar branch to the left kidney, which entered the kidney just above the hilum. There were two right renal arteries (Fig. 1,2). Both the right renal arteries passed behind the inferior vena cava and entered the kidney through the hilum. The left renal vein descended down and to the right from the kidney, passed behind the abdominal aorta and joined the inferior vena cava with an acute angle (Fig. 1,2). The termination of this vein was at the level of the origin of the inferior mesenteric artery. It received two veins from the kidney, one vein each from the left suprarenal gland and the left testis. The left testicular vein also joined the left renal vein with an acute angle. On the right side, there was a single renal vein, which joined the inferior vena cava. 
(AA - abdominal aorta, IVC - inferior vena cava, RK - right kidney, LK - left kidney, RRA - right renal artery, LRA - left renal artery, RRV - right renal vein, LRV - left renal vein, RTV - right testicular vein, LTV - left testicular vein, CA - celiac artery, SMA - superior mesenteric artery, IMA inferior mesenteric artery, LSRV - left suprarenal vein.

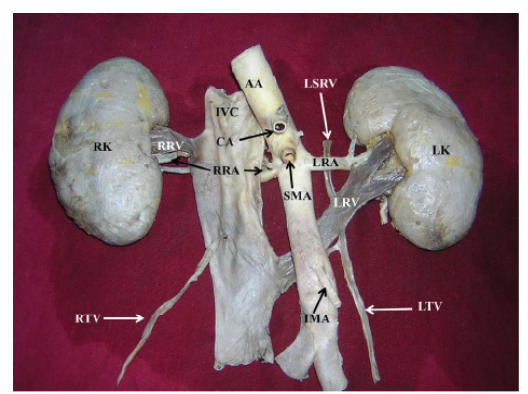

Figure 1. Dissection of the retro-aortic left renal vein.

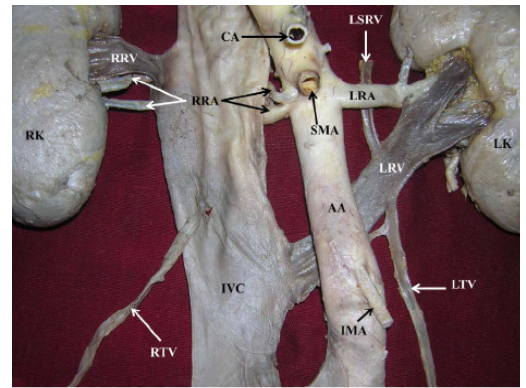

Figure 2. Dissection of the retro-aortic left renal vein (closer view).

\section{DISCUSSION}

Knowledge of the renal vascular anatomy may greatly contribute to the success of surgical, invasive and radiological procedures of the retroperitoneal region. Preoperative knowledge of the presence of major venous anomalies facilitates the safe performance of aortic surgery.

In the current case, the right kidney was supplied by two renal arteries; both of which arose from the abdominal aorta. Bayramoglu et al. have reported bilateral additional renal arteries originating from the abdominal aorta and an additional right renal vein accompanying the additional right renal artery. ${ }^{3}$ Multiple variations of the right renal vessels have been reported by Nayak. ${ }^{4}$ The variations in the renal arteries are mainly due to the various developmental positions of kidney. ${ }^{5}$ Knowledge of variations of renal arteries is important while performing retroperitoneal surgeries like kidney transplantation.

Left renal vein usually crosses in front of the aorta to reach the inferior vena cava. However in about $1.72 \%$ of cases it can take a retro-aortic course. ${ }^{6}$ Another important variation of the left renal vein is the presence of a circumaortic renal collar in $3-6 \%$ of cases with a pre and a post aortic component. ${ }^{7}$ The left renal vein is derived from: a) Mesonephric vein that originally drains the left kidney into left subcardinal vein, b) A small part of left subcardinal vein and c) Intersubcardinal anastomosis. The intersubcardinal anastomosis has pre-aortic or post-aortic components. Normally the pre-aortic component persists. When the post-aortic component persists and the preaortic segment disappears, it results in the formation of retro-aortic left renal vein. ${ }^{8}$ Retro-aortic left renal vein may be compressed between the aorta and the lumbar vertebra leading to left renal venous hypertension which is known as "Posterior Nutcracker Syndrome" which is manifested by left flank and abdominal pain with or without hematuria. ${ }^{9-11}$ Increased pressure in the left renal vein can lead to the left sided varicocele and this in turn may lead to difficulties in spermatogenesis. ${ }^{12,13}$ Presence of retro-aortic left renal vein in females may result in Pelvic Congestion Syndrome which is characterized by lower abdominal pain, dysmenorrhoea, dyspareunia, vulval, gluteal or thigh varices and emotional disturbances. ${ }^{14}$ The retro-aortic left renal has high chances of getting compressed by the retro-peritoneal growths leading to congestion of kidney. If prolonged, it may lead to a form of Chronic Interstitial Nephritis. ${ }^{15}$

The retro-aortic renal vein usually presents a horizontal course and the gonadal vein drains into it perpendicularly. Our case is special in having the oblique course of the left renal vein and the oblique termination of the left testicular vein into it. This condition might result in venous congestion in the left renal vein and the left testicular vein, altering the functions of both left kidney and testis. Clinicians must be aware of presence of such a renal vein for the accurate diagnosis in cases of altered renal functions and left sided varicoceles. Preoperative imaging techniques might reveal the anomalous renal vein and is of use in minimizing the accidental damage during surgery.

\section{REFERENCES}

1. Standring S. Gray's Anatomy-The anatomical basis of clinical practice. $39^{\text {th }}$ Ed. Elsevier: Churchill Livingstone, 2005, pp 1274-1276.

2. Thomas TV. Surgical implications of retroaortic left renal vein. Arch Surg. 1970 Jun;100(6):738-40.

3. Bayramoglu A, Demiryurek D, Erbil KM. Bilateral additional renal arteries and an additional right renal vein associated with unrotated kidneys. Saudi Med J. 2003; 24:535-7.

4. Nayak BS. Multiple variations of the right renal vessels. Singapore Med J. 2008; 49 (6): e 153.

5. Moore KL and Persaud TVN. The Developing Human. Saunders, An Imprint of Elsevier. $7^{\text {th }}$ Edition. pp. 293.

6. Martinez-Almagro A, Almenar Garcia V, Martinez Sanjuan V, Hernandez Gil de Tejada T, Lorente Montalvo P. Retro-aortic left renal vein: a report of six cases. Surg Radiol Anat. 1992; 14: 361-366.

7. Pick JW, Anson BJ. The renal vascular pedicle. J Urol. 1940; 44: 411-34.

8. Singh I, Pal GP. Human Embryology. $8^{\text {th }}$ Ed., Chennai, Macmillan India Press. 2009; 228-9. 
9. Mendizabal S, Roman E, Serrano A, Berbel O, Simon J. Left renal vein hypertension syndrome. Nefrologia. 2005; 25:141-6. (Spanish)

10. Hemalatha K, Narayani R, Moorthy M, Korth MP, Jagadeesan K. Retro-aortic left renal vein and hypertension. Bombay Hospital J. 2008;50:6-9.

11. Yagci B, Tavasli B, Karabulut N, Kiroglu Y. Clinical significance and renal haemodynamics of incidentally detected retroaortic left renal vein: assessment with venous Doppler sonography. Br J Radiol. 2008; 81: 187-91.

12. Karazincir S, Balci A, Gorur S, Sumbas H, Kiper AN. Incidence of retroaortic left renal vein in patients with varicocele. J Ultrasound Med. 2007; 26: 601-4.
13. Arslan H, Etlik O, Ceylan K, Temizoz O, Harman M, Kavan M. Incidence of retro-aortic left renal vein and its relationship with varicocele. Eur Radiol. 2005; 15: 1717-20.

14. Koc Z, Ulusan S, Tokmak N, Oguzkurt L, Yildirim T. Double retro-aortic left renal veins as a possible cause of pelvic congestion syndrome: imaging findings in two patients. Br J Radiol. 2006; 79: e152-155.

15. Huber GC. Piersol's Human Anatomy. Vol. 1, $9^{\text {th }}$ Ed., Phiadelphia, London, J.B. Lippincot Co. 1930: 902-4. 